\title{
VIDEO AND STORYTELLING IN A DIGITAL WORLD: INTERACTIONS AND NARRATIVES IN VIDEOCLIPS
}

\author{
Rodrigo Oliva, José Bidarra \& Denize Araújo
}

\begin{abstract}
This paper presents a study about narratives in music videos. It discusses the arrangements of audio-visual languages from settings established by characteristics of the media, emphasizing the role of platforms for the diffusion of information and entertainment such as YouTube. It highlights a dialogue within cinema's own language and shows that, in contemporary scenarios, music videos actually tell stories. It is argued that contemporary music videos, in great majority, increase the duration of music, with pauses, performances of characters, insertion of dialogues and other structuring elements that are not typical of the classic and conventional paradigms of a language. For our purposes, the objects of this study are the music videos of Canadian filmmaker Xavier Dolan. The theoretical foundation is established through authors involved in debates around a culture of convergence, transmedia storytelling and interactions among the audio-visual languages.
\end{abstract}

\section{KeYwORDS}

Cinema; music videos; narrative; storytelling; transmedia

\begin{abstract}
RESUMO
Este artigo apresenta um estudo sobre as narrativas em videoclipes. Discute-se os arranjos das linguagens audiovisuais a partir de configurações estabelecidas por características dos meios de comunicação, enfatizando o papel das plataformas de difusão de informação e entretenimento como o YouTube. Sublinha-se ainda um diálogo com a linguagem do cinema e evidencia-se que, nos cenários contemporâneos, os videoclipes contam histórias. Discute-se que os videoclipes contemporâneos, em grande maioria, prolongam o tempo da música, com pausas, atuações de personagens, inserção de diálogos e outros elementos estruturantes que descaracterizam os paradigmas clássicos e convencionais da linguagem. Para a análise, o objeto do estudo são os videoclipes do cineasta canadense Xavier Dolan. A fundamentação teórica é estabelecida a partir de autores inseridos nos debates da cultura da convergência, de transmídia storytelling e das interações entre linguagens audiovisuais.
\end{abstract}

\section{Palavras-Chave}

Cinema; videoclipes; narrativa; storytelling; transmídia 


\section{INTRODUCTION}

In the last decades, it has been possible to verify some transformations in certain forms of communication. We are following the creation of new arrangements in renewed perspectives in the traditional media and the appearance of new communication technologies that are allowing the reconfiguration of interaction processes between emission and reception. These new dynamics promote, in the realm of codes and languages, a reconfiguration in aesthetic, social and poetic processes in relation to messages and their articulations in the way discourses are constructed and planned (Oliva, 2015).

Within this scenery of a culture of convergence proposed by Henry Jenkins (2014), spreadability becomes evident considering the creation of an environment in which interactivity and individual participation are the most emphasized references. According to Jenkins, spreadability is related to content dislocation, such as adherence models that circulate through interactivity between people in communication processes. However, it was possible to perceive that new spreadability differs from its old communicative status that was limited the content projection in unique platforms to ample audiences, discussed by Jenkins based on the adherence concept by researcher Malcolm Gladwell.

Adherence privileges content allocation in one place only entices and tries to send audience there in order to be accounted for. The destination visualization often gets into conflict with the dynamic navigation of individual users of the Internet, namely the most important conflict, frictions related to content circulation through social connections of audience members. (Jenkins, 2014, p. 28)

Jenkins establishes a comparative analysis about these two moments that, viewed in an isolated manner, allow for a reflection about the moment of communication nowadays, considering that the structural elements of the communicational process tend to move. In their social context, new media trace new paths for the relation development between people and media, building new foundations and promoting openings for reinvention in the processes of message creation (Sousa, Zagalo \& Martins, 2012). Nowadays, reception participation configures new strategies, considering that people's spontaneous contributions interfere in the construction of new narratives (Brandão, 2010).

Raymond Bellour (1997), in his classic book L'Entre-Images (1990), introduces considerations about a moment in visual and sound arts in which elements that are characteristic and constitute one language are incorporated by others, as for instance if the video was incorporated in a movie or a fixed image incorporated in a movie. This kind of hybridization is somewhat common today in the sphere of media. Considering the discussion established in this study, about message constructions departing from these new technologies, we would like to initiate a dialog with Bellour, who discusses the relationship between the spectator of an image and that of a movie. Departing from this theory, we will question how these relations are established in the experiences with the video productions projected in platforms such as YouTube.

According to Bellour, the cinema audience is active, has little time for contemplation and cannot close the eyes for fear of missing something relevant. Completely 
different from the contemplation of a photograph, in which the gaze tends to scrutinize through the contours and the centre of the frame, photography demands a form of contemplation.

The cinema spectator wants everything in a hurry. He follows a film that sometimes may be too slow, but it will certainly become too fast if he thinks about the message. Do we add anything to the image? - I do not believe, I do not have time, facing the screen I am not free to close my eyes; otherwise, in opening them I will not find the same image. Facing a photograph, on the contrary, we close our eyes many times: time (theoretically infinite and that can be repeated) can produce meanings and thanks to the image the one who sees can see himself in it. (Bellour, 1997, p. 84)

We come across an important question considering Bellour's thought: the gaze that is established for the two media, though the two share resemblances, is of different categories. This relation can be established by a more intense gaze in photography than in film.

New media will certainly produce new approaches in this dialog. According to Julian Wolske (2014, p. 203), the consumption of TV media products, still hegemonic, has been losing space to a quick audience developing in the online environment. If we take video consumption, the jump is even higher, considering the search for audio-visual material today. According to Wolske (2014, p. 203), the two are responsible for this new context. Firstly, the possibility to watch online video content anytime and, secondly, the search for short, simple and not so professional products. The consumption of mobile products, for instance, alters the audio-visual experience because the small screens do not offer a possibility to see fine details. Images are presented with less resolution and poor photographic quality, diminishing the impact in scenes with perspective, because it alters the depth-of-field. We can also perceive that actors' performances as well as audiovisual resources do not offer the same kind of quality as in a larger screen.

In this study, we attempt to present some characteristics of the new audio-visual communication context. The main focus of this study is the videoclip language and its articulation with the cinema language. We establish some considerations about the dynamics that involve narratives, trying to understand their complexities, considering that one of the main points of this discussion is a specific point about videoclips that narrate stories. We verified a tendency which opposes the view of short and quick videos, but that has some features such as extension of time, with pauses, characters' performances, dialogue insertions and other structural language elements that mischaracterize classical and conventional videoclip paradigms.

The North American researcher Carol Vernalis has been translating this dynamic of videoclip language to new scenarios. Vernalis (2004) argues that there are certain patterns behind these new scenarios and points out that the formats of videoclips are very fluid. Starting from the exact time of the songs, finds that narratives in videoclips are not complete. This dynamic is feasible, considering that films are constructed according to 
various possibilities of language articulation, such as performances of singers inserted in the audio-visual sequence, lack of characters, lack of dialogues and diversified insertions, considering that what characterizes the videoclip language is its hybrid nature. We argue that this dynamic proposed by the author can explain the consumerist scenario of the videoclips exhibited by MTV Channel.

With the advent of the Internet and the paths pointed out for the spreadability of content, we verified that there is a certain autonomy not only from the part of the receiver but also for the producer. A videoclip does not necessarily need to be tied to the total time of the music or to the format that is in the foundation of classic TV projection, considering that it is set in well defined blocs, structured by the format of advertising. MTV implemented a mould of construction for the format needed by the advertising business, in close similarity to the radio broadcasts, as if it could be considered a radio with images.

In this context, we present a debate about the concept of storytelling, emphasizing the importance of understanding of how the practice of storytelling becomes evident in the universe of videoclips and advertising nowadays. We think that the practice of experimentation, disseminated by videoart, was very far from narrative issues. Initially, what characterized videoclips was exactly this experimentation approach. Or better, narratives in videoclips tend to be expanded within these new scenarios. These considerations can be looked up in the text The New Digital Storytelling, by Bryan Alexander (2011).

After this, we discussed some remarks about the YouTube platform, for its project nature opens possibilities of infinite creations. The social role of YouTube characterized by the storage, projection and historical recovering of audio-visual is of great impact. In this sense, it is important to think how the nature of the platform allows structures for narratives in audio-visual material.

We also establish a discussion around the return of the concept that represents these new contexts, called "spread out" or "expanded narratives" (Oliva, 2017, p. 110), that bring together cinema and videoclip languages and translate an idea about how narratives are articulated in contemporary productions such as the clips that today are made to be enjoyed via internet. We argue that narratives have become expressive ways to match these new times, each day faster, with images showing close ups and object details, following a less developed plot, with a treatment of flashy colours or in high contrast, everything done in order to attract the attention of spectators that use small screens.

Transposing now our ideas to the studies on videoclip language. In today's online environments, we observed that videoclips tend to expand narratives in time and space, either for the total or partial duration of the music. To back the discussion of this concept, we analysed two videoclips by Canadian filmmaker Xavier Dolan. Both videoclips are contemporary and translate the mentioned considerations of this study. The first one is College Boy, and it was produced for the French band Indochine, in 2013. This videoclip is entirely done without the presence of the musical band and offers a well-structured linear narrative, with facts, characters, actions and images of great impact. The second 
videoclip was directed for the dissemination of the song Hello, by the English pop singer Adele. In this one, the insertion of dialogs in the background, mixed in low volume with the music-theme, uses the same resource of a typical film narrative. The performance of the main character of the videoclip is done by the singer herself, sometimes acting as actress, sometimes as singer, and other times as interpreter.

We end this introduction with the reflection that, lately, the media languages convergence of four times has a fluid profile and an intense hybridization. We believe that this justification is important, since we are observing much more a scenario of reconfiguration and remodelling than a change of paradigms. We believe that, in the contemporary context, the videoclip and the cinema languages establish a flux of interconnections that allow for obvious aesthetic and formal (re)creations.

\section{STORYTELLING, NARRATIVES AND VIDEOCLIPS}

The concept of storytelling has been discussed lately in many ways, mainly in its association with new technologies. However, telling stories is a recurrent activity in the world history. Since early times, in the oral and written traditions, we witness the development of narratives. It is interesting to perceive how narratives, nowadays, have spread in new formats. This fluid profile, a kind of pouring out, establishes a relevant dialog with new technologies.

Today we watch the global reborn of a model coined as digital storytelling, that could be translated as "digital narratives" and, in this case, it is not a trend; stories and narratives have been used in teaching and learning for many years, frequently in areas such as administration, psychology or health. The stories help us to understand individual experience and to develop a perception of the world around us. They also help the building of relations with a repertoire and to improve memory. As a result, good stories are better remembered by students than regular classes. On the other hand, considering the main role of narrative in our daily lives and the technological explosion during the last decades, it is not surprising to find digital narratives as pedagogical strategies in many university courses, as they are important in theatre, films and games.

But what are "digital narratives"? Essentially, we are referring to digital artefacts that include: a persuasive narration of a story; a significant context for the understanding of a story; text, images and graphics that attract or expand the emotions found in narrative; voice, music and sound effects that reinforce themes; and mechanisms that invite reflection and target-audience participation.

Narratives refer to a series of events that occurred (in the past, as a memory), are occurring (in the present) or will occur (in the future). Moreover, telling stories implies the integration of four classic elements that are still valid in our digital era, such as: a plot; a narrator; a context; and the characters.

In a simple way, we could say that a digital narrative is the one that uses a digital device. Nowadays, this expression contemplates a large array of projects and products that include scrapbooks and photography portfolios, radio productions and podcasts, 
multimedia projects and videos. The Web 2.0 digital tools that can be used by anyone are now free software that opened a new world of possibilities for good educational practices. A relevant example is the use of the Facebook timeline to narrate a chronology (trip, experience, research, event).

For the researcher Anna Ursyn (2014), myths, legends and traditional tales have started to be transposed to the online environment. The huge potential that the means of communication offer today, brought with the Internet, offers support for the way interactions between people and digital platforms are established. The contact with traditional forms of image, sound and language gain, in the Internet, more interactive profiles, where technologies that allow visualization are in the hands of producers as well as users. This dynamic interaction changed the old status of communication, from isolated producers and recipients to a more communicative format in diverse schemes.

All these traditional myths, legends, fairytales, folktales, parables, and fables found their place in the current multimedia communication storytelling techniques, so digital storytelling could take over the old art in current modes of expression. Present-day story visualization technologies combine storytelling with multimedia formats such as text, images, sound, and movement with narratives, commentaries, and depictions in a dynamic, often interactive environment, so the viewer becomes the co-creator of the art. They use Powerpoint, Flickr, Movie Maker, digital photos, and videos, to address issues and challenges, enrich information, evoke responses, and emotionally involve people, serving for making news, business-related, marketing, educational, and training applications. (Ursyn, 2014, p. 440)

The author presents these relations pointing out that in the contemporary context there is a combination of narrative forms and multimedia technology, what provokes more interactivity through people participation in the sense of generating content in different formats that can be published, visualized and commented. The Internet produced a revolution in the format in which content is presented, allowing a certain democratization in the information offered, that in the past was controlled by systems belonging to powerful communication enterprises. In this sense, even the media of mass communication started to realize the existing demand for the interactivity coming from the Internet and started to structure new connections with the public. This originated a complex flux of interactivity described by Henry Jenkins (2008) in the book Convergence Culture. Jenkins develops various concepts for these new contexts providing the idea of a transmedia narrative that describes this context of content diffusion, which is happening through different channels. A transmedia narrative is not a simple projection of content in diverse means as a linear transposition. It is in fact a narrative displacement between content presented in different platforms of communication (Rodrigues \& Bidarra, 2016).

It is important to realize that, in these narrative displacements, narratives have to reposition themselves to be placed in different formats and arrangements. It is common today to see a huge offer of courses about storytelling, since this concept is viewed as a 
tendency in business, social environments, advertising, and also related to education. According to Anna Ursyn (2013), visual storytelling introduces a fourth dimension, due to the possibility of a time and space development to follow the adventures of the created characters. The characters, in the computer screen, transmit emotions, realism, feelings that are perceived by the audience. In this sense, digital art takes its space, developing techniques and poetics in order to build possible visual narratives in interactive environments.

Brian Alexander (2011) translates the concept of digital storytelling providing various characteristics and allocating definitions according to the development of the Internet itself. In the first place, the author brings up an important issue: how can a story exist out of time, beyond temporality? It is true that linear narratives were central in the construction of typical works in History, Arts, Literature, and so on. Even within communication products such as soap operas, films and videos, there is a tendency to the structured construction of narratives that are often produced to appeal to large audiences.

In the cinema, we are aware of a classic narrative system promoted by Hollywood. The well-structured narrative in its organized and rigid elements gains credibility in the greatest American films that show, even today, a typical pattern of structural components of a narrative in harmony with aspects of an audio-visual production of classic profile. Bruce Block (2010, p. 233) suggests that narratives are structured in three main parts: exposition, conflict and resolution. The exposition emphasizes the presentation of facts needed for the development of the story; the conflict represents the climax and the resolution is the ending. Therefore, American Cinema organizes its narratives in a similar way and it can be seen as a referential for other audio-visual narratives, considering that in about a hundred and twenty years of existence there is a powerful legacy of stories that are told and retold through filmic narratives.

Regarding videoclips, as mentioned before, storytelling becomes more complex if we analyse some important remarks such as: the music timing, the advertising and marketing of the songs, and the artist's image and performance. The latter may create a persona inside a narrative, or just show the role of the artist in the interpretation of the music. Videoclip language is usually fast, active, based on slow or fast rhythmic arrangements. It is necessary to pay attention to the connection between the rhythm of the songs and the visual images. Recently, pop singer Lana del Rey was the protagonist of a short movie called Tropico, in which three of the songs of her album were incorporated into a unique context. Lana represents a character with powerful musical performances, some acting and a lot of symbolism. Edited as a film for the online environment, Tropico is 30 minute long and can be watched in its complete version or fragmented in three distinctive parts related directly with thematic songs.

The fact just mentioned makes it clear that videoclip language is very persuasive, having been incorporated also as a language of the internet, promoting arrangements which are connected with specific characteristics of digital media and social networks. We are aware that most of new videoclips are presented with the intention of telling stories. It is in this sense, and also because this is less studied, that we tried to establish a 
relation with storytelling. Normally, most studies are concerned with the videoclip itself leaving aside storytelling.

Bryan Alexander establishes some historical remarks about the development of the concept of digital storytelling. The author develops his thoughts starting with the progress of the Internet and its technological developments. Its growth was so fast that it allowed for many forms of interactivity from the moment that online platforms were available. The new wave of digital storytelling is explained by Alexander (2001, p. 29), as a follow up of the Web 2.0 creation:

Web 2.0 sites, in contrast, allow multiple channels of communication between site visitors, site creators, and other parties. They are fundamentally designed to encourage such connections through wiki editing, comment threads, media embedding, tagging, Facebook Liking, Digg and Reddit services, and more. A site's visitors can leave comments or add tags, or link to it from their own site. Other visitors can see these comments and other connections, like a party guest entering a room where a conversation is in full swing. Multiple users can build objects and collections together, from an iterated wiki page to a shared Flickr photo pool to a co-drawn Gliffy image. (Alexander, 2011, p. 31)

Although the profile of diffused messages is ephemeral in the online environment, other forms such as blogs, Twitter, Facebook, among others, caused an explosion of content through audience participation. Therefore, within this huge volume, some stories are more emphasized, are marked, and became targets for discussion and argument. This is the characterization and start of "viralization". To become "viral" is interesting, because among a diversity of forms and happenings, "viralization" is the appearance, the overlay, the amplification, creating an impact in terms of audience. According to Bryan Alexander, digital storytelling combines sequential elements, and this sequence of events is the main factor for the understanding of these new narratives:

sequence is important for another reason, namely, the importance of stories' extension in time. A single image, object, or musical tone does not usually constitute a story. They are story pieces, media fodder awaiting use. Now, an audience can turn a single item into a story through the process of reception. (Alexander, 2011, p. 13)

As pointed out by Alexander (2011), a simple photograph does not imply a narrative in itself. It needs to be introduced in a time sequence, in a logic association with other sequences. To create narratives, it is necessary to have tools and the Internet offers many of them. Taking photos, manipulating images, introducing texts, or inserting an emoticon in a remark are some of the many examples. From this point, the audio-visual media become the place for interactive videos, new possibilities of integration and democratic production of audio-visual materials. On the other side, when we discussed the videoclip language, we talked about the amplification of the potential to tell stories. In fact, this 
always occurred in the context of the videoclip but in a less emphasized way, in fact what characterized the videoclip language was narrative discontinuity.

Opposing the fragmentation tendency, we think that storytelling in videoclips is connected with key elements of the narrative construction such as time, space, dramatization, characters, actions, dialogs and others. One of the founding principles to make easier the reading and understanding of narratives in videoclips is exactly the sequenciality, whose frontiers expanded as determined by the exact time of the songs, creating possibilities for ruptures, pauses, interactions among characters, and other resources that rule filmic time and space. The YouTube platform gains a very important role in this process, considering that it is the new media in which, to a certain degree, it is possible to mould the potential of the audio-visual language.

\section{YouTube AS A DIFFUSION PLATFORM}

One of the most important aspects of audio-visual production is "spreadability", which has to be planned strategically. In past times it was common to have cinematic and audio-visual projections, such as projections in cinema theatres, television, videotape and even in museums, As explained before, each element has its functions well defined. In the new media, audience participation is, certainly, one of the greatest innovations. We are living in a moment of interactivity in vast proportions. On the other hand, distribution operates through diversified systems.

Henry Jenkins (2014) clearly shows the difficulties that online media corporations have in order to make sure that diffusion processes follow copyrights and other legal norms. The new copy schemes are important because they are presented in a more democratic way. The YouTube platform is, undoubtedly, the more famous means of audio-visual diffusion nowadays. Its interface has an easy accessibility and great usability. Besides, accessing a vast amount of audio-visual content, you can also be part of the platform and have your profile to publish private videos or simply create preference lists.

Jean Burges and Joshua Green (2009) emphasize the nature of the social aspects of promotion that are related to our daily lives and allow the exhibition of private facts in YouTube. The possibility of watching others audio-visual material has became more democratic as well as the offer and insertion of people's own content, considering that each participant can either watch, or promote own content, or disseminate his/her own message (Burgess \& Green, 2009).

Beyond the fact already evident of the possibilities that YouTube brings in order to allow public interaction, in a way that creates a possibility for comment on publications, including video and programme exhibition and own experiences to be shared, the platform also became a mass media with specific channels for the diffusion of videoclips. One of the most famous channels is Vevo, which is actually an entertainment site that, through its partnerships, can share and send its contents to YouTube.

This new modality of visualization replaces the MTV channel as the main reference in videoclips diffusion. MTV closed its doors in some countries and nowadays it does 
not have the same popularity as it had in the past. We understand that MTV channel, as it presents a flux of messages in a restricted way, conditioned by advertising blocks, has limited creative possibilities in the sense of not being open to narratives; also considering that the exact time of songs was a condition for the insertion them in the programme. On the other hand, in the history of videoclip, there were some representations that did not follow these rules, such as, for instance, the emblematic videoclip Thriller, by Michael Jackson. According to sources in the book by Brian Alexander (2011), an average of two billion users watches videos daily on YouTube. There is a probability that, nowadays, this average has grown exponentially, especially with the widespread diffusion of mobile phones. But today we see new kinds of interaction between online media, from traditional computers to tablets, cell phones and mobile gadgets.

Nicholas Rombes (2009) discusses how cinema has been moulded after these procedures of digital nature. The author presents a series of details that characterize digital manifestations in the nature of the audio-visual image. One of them is the change of status of the huge theatre screens to the small digital screens. Rombes (2009, p. 120) argues that the seductive profile of the cinematographic image in ample screens has suffered a transformation that alters the way we receive images:

the shrinking of movies down to little screens that are portable erases any lingering hints of mystification: there are no mysteries to movies today. In some ways, this is in keeping with the project begun by minimal art and minimalism: a simplicity so severe that it becomes almost ornate. Small, portable screens cannot help but reveal the contours of their making: unlike the theatre screen, there is no dark surrounding the hand-held video screen: portable theatre screens mean that theatre follows us everywhere. (Rombes, 2009, p. 120)

For the author, this cannot be seen in a negative light, considering that, although the minimalist form in which the image is projected, its performance is always in movement, which makes the image to have more potential in its more frequent exhibitions. We believe, from his remarks, that the possibility of diffusion in small formats is not concerned with issues of image quality and perception, emphasizing only the many times this image will be seen.

Seen through this logic, the YouTube platform allows a high degree of interactivity between users and audio-visual content. Established in small formats, this appropriation has a peculiar contact, being transitory, fluid and connected to the intense fragmentation of images and sounds.

\section{EXPANDED NARRATIVES IN VIDEOCLIPS}

In proposing this text, we believe that in online environments, even if videos and films tend to have fast, fragmented and dynamic presentations, we can acknowledge tendencies that are against this. One of them is acknowledging that some contemporary 
videoclips extend the time of music and focus its visual elements in well-defined narratives, what we called expanded narratives. It is common, among them, to have a prologue that announces the initial narrative characteristics. David Bordwell (2005) develops a study about peculiarities of narrative processes established in the classic American Cinema. According to the author, there is an assembly of marked structures in literary narrative studies that present themselves as components of cinematographic narratives. Such particularities are close to a cinema that gives priority to the dramatization centred in principles of linearity and sequentiality (Bordwell, 2005).

Bordwell signals the various possibilities of narrative studies connected to Cinema, from structuralist characterizations to content and apprehension reception. This is important because it determines principles for the study of narrative components of a film, whose central point of discussion is the fact that in the classic narrative the spectator builds time and space with clarity and coherence.

Bruce Block (2010, p. 233), studying visual narrative, presents an important connection between the visual structure and the typical components of a narrative, such as: exposition, conflict and resolution. Block proposes exposition as the beginning of a story. Conflict is the key moment of narrative, the one that gives impulse to the story. A conflict can be internal (of character) or external (connected to a situation). The resolution is the moment in which the audience needs to reflect about narrative conflict, meaning it is the end of a story (Block, 2010).

For the author, the narrative and the visual exhibition should occur at the same time. In the exposition, visual strategies that mark important characterization of spaces characters and situations should be created and planned. However, in the conflict presentation moment such marks should be emphasized, magnifying the contrast, so a perception of major intensity will be created. In the resolution, the affinity line is restored, establishing relations of less visual intensity.

André Gaudreault (2009) questions the definition of cinematographic narrative. According to the author, two characteristics are relevant to be understood for the comprehension of how cinematographic narratives are presented: the filmic performance and the scenic performance. Both regulate the place in which stories are told. The first one refers to the essential elements of cinematographic language, and is established through configurations of plans, images, composition and colour elements, among others. The scenic performance incorporates acting and dramatizations of characters, visible in their actions in space and time.

It is relevant to discuss these considerations in an attempt to think how narrative is established in the videoclip language. Vernalis (2004. p. 13) suggests that narratives in videoclips are disjunctive, there is no connection between word, images and music. According to the author, videoclips tend to create a story sensation, but the story is not completed.

In establishing the concept of "expanded narratives" (Oliva, 2017), we argue that there is an amplification of forms in the ways videoclip narratives are presented. As said above, it is common to have a prologue without music, with the presentations of 
characters, actions, settings and dialogs inclusion. We can associate this to the question of visual exposition and narrative by Bruce Block. When the music starts, a series of strategies about filmic composition can be adopted in order to acquire synchrony between musical and imagetic rhythm. In contemporary videoclips, characters' performances are not conditioned to the exact time of the music. There is a possibility of dialogue insertion incorporated or not in the songs. Generally, in the final stage of production, the narrative can have a resolution without the music

In this sense, in the contemporary scenario, many instances of this discursive strategy can be adopted (Barboza (2015). If, in the past, the videoclip language was characterized by the deconstruction of the narrative, nowadays there is an amplification of this format for new kinds of videoclips. We believe that this characterization is due essentially to new mediation platforms that allow for a different reception, far from that imposed for the specific canons of videoclip exhibition on television.

\section{Case analysis}

We propose, for this study, an analysis of two videoclips directed by the Canadian filmmaker Xavier Dolan. Both videoclips tell stories and present a narrative following the parameters of what we coined as "expanded narratives". The first is called Hello and emphasizes the protagonist as the singer herself, acting as character and interpreter at the same time. She is the English singer Adele. The second clip does without a band and presents itself through characters with no inclusion of the French band Indochine.

The videoclip with the song Hello starts with a prologue without the music theme. At that moment, we are presented with a specific situation. The first plan is an out of focus image of a window. We can see an open window through the frame and, in perspective, a car approaching. Adele talks on the phone: "I've just got here, and I think I'm losing signal already. Hello? Can you hear me now? Sorry. I'm sorry, I'm sorry". We do not know whom she is talking with, but it is certain that this is a key-situation. She says she has just arrived and is already losing signal, and asks to be forgiven for something. This prologue establishes a narrative profile: a character presentation, an enigmatic situation with the image of a car and the words of the character, the loss of the signal and the request to be forgiven.

The colour of the videoclip is "sepia", what indicates a situation of indifference. The prologue ends with images of the protagonist getting out sheets from pieces of furniture. These plans imply that the place is abandoned, which is significant for the understanding of the film narrative. After that, we see a close-up of Adele, in which she moves her neck as if she was tired and then looks straight to the camera, directing her gaze to the audience. At this moment, we hear the song and the singer executes her performance saying Hello!

During this initial moment of the music presentation, we see a series of detailed plans showing the character doing domestic chores, such as breakfast, taking notes and talking on the phone. Synchronized to these images, we see the appearance of a second character, a young black man. The whole approach to this character is done by means of 
subjective camera, as if the character was looking directly to the character/singer. These situations introduce to us the daily routine of the house, but in two ways, initially showing a certain harmony between the couple and later presenting a conflict, with fights and more dramatic situations. In a moment, for instance, the character is shown under rain. These man's image is presented through temporal flashbacks incorporated to the filmic narrative.

One of the interesting points of this videoclip is the resource of dialogues that are not shown clearly. We hear noises that are under the music and making possible the understanding of the narrative situation. Even if we do not have the total content of the dialogues, we can understand the discourse implications, established by the relation and performance of the couple.
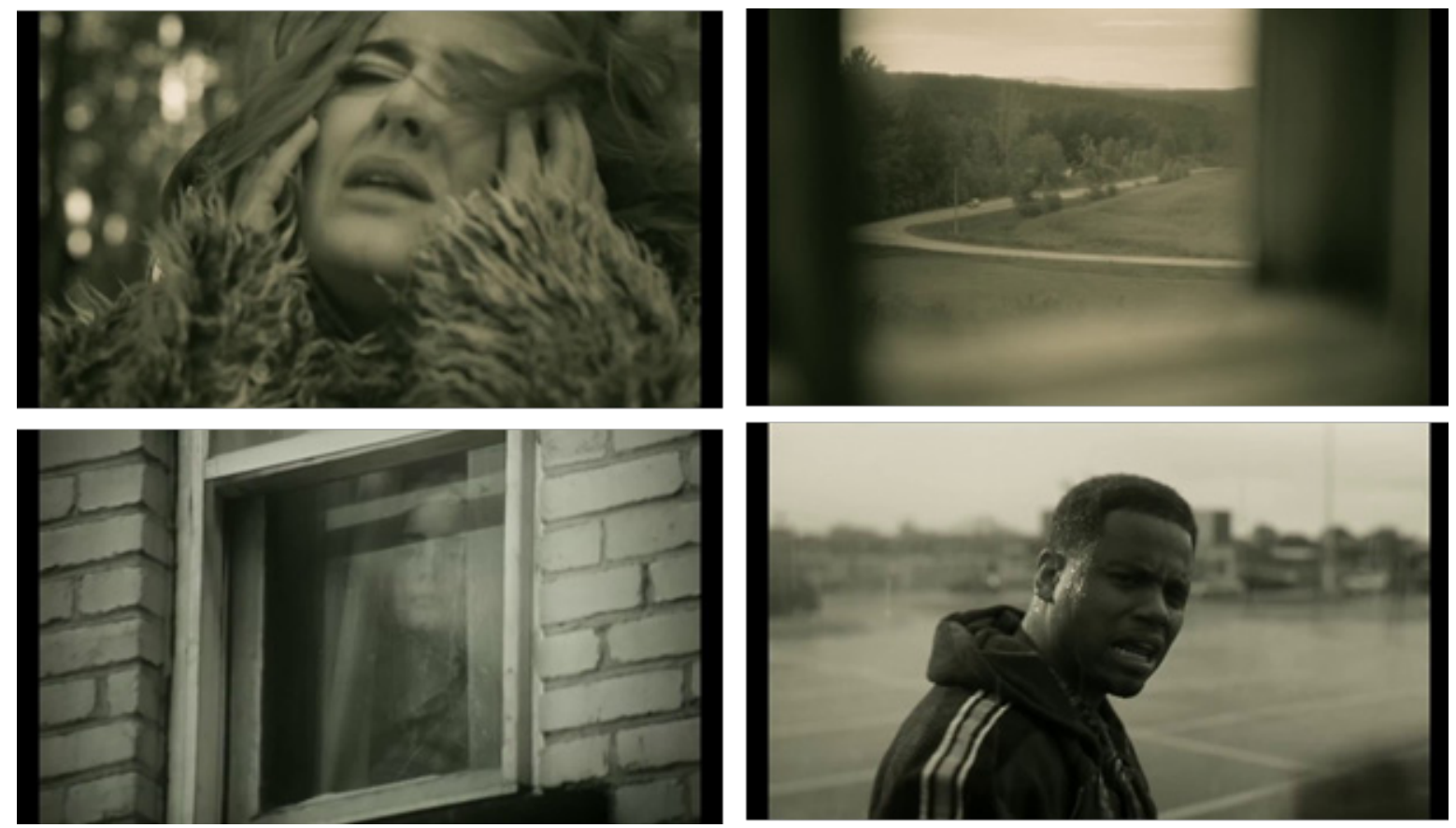

Figure 1: Videoclip frames, music Hello!, Adèle, directed by Xavier Dolan, 2015 Source: https://www.youtube.com/watch?v=YQHsXMglCgA

During the videoclip, there is a narrative space out of the context of the couple story, determined through the phone representation and the garden covered by creepers, in a sign of the abandon of the place. The singer performance is established in this exterior space, a kind of forest with dry leaves resembling an autumn season. This moment dislocated of the narrative provokes an amplified situation through the interpretation and the dramatization performed by Adele in her song.

The climax is revealed in a quick way almost at the end before the resolution. We see an image of the character next to the window. Externally, the young man is approaching the house, closing the trunk of the car and also his cell phone. The character shows up in the window. This scene gives an impact to the narrative for establishing a connection with the prologue. However, it allows possibilities for ambiguous interpretations, 
considering that it is complex to understand a temporal question related to the beginning in which the scene shows a car arriving in the house after a detailed plan of the window.

What is important in this videoclip is to verify that the characters, as well as their actions, are presented in a way that makes us understand the story. The narrative is amplified through strategies that allow present and past to be distinct and offer us identification with the basic structure of a story.

The videoclip College Boy presents the same narrative scheme of the videoclip Hello! Produced in the 1:1 format with black lateral bars, the film also has a prologue without the musical theme. We can see the main character but there is no participation of the members of the Indochine band. The place presented initially is a classroom, in total silence, while the teacher writes some information in the blackboard. The character is sitting in a chair looking at his notebook. We can see a series of frames of other students with close ups of them kneading paper and, later, in an extreme situation when some students throw the papers to the young character. A pen falls on the floor and breaks the silence, the teacher hears the sound but remains in the same position, not reacting to what is happening. This posture of the teacher is important to the understanding of the story. We see a close up of the face of the character with liquid slipping from something that was thrown on him. Later, the bell rings announcing the end of class. In this prologue, the camera is in slow motion, determining the visual aspect of the videoclip and will reveal an antagonist character: one of the students that will be detached in the presentation for the slow movement of the camera and the paper attack to the main character.

The whole film is black and white with some grey elements. There is a tone of indifference in the film, as if all the characters were insensitive towards the violence inflicted upon the college boy. The prologue ends with the sound of the bell indicating that the class is over. Then, departing from this index signal, we can start hearing the song.

After the beginning of the song, the marginal situation of the college boy becomes evident. We can see him walk through the school corridors up to his locker. We can also see that his locker is damaged and he holds a broken mirror. The camera in close up allows us to see the image of the student projected in the broken mirror, following up, it shows us the character running away from something in slow motion.

In the sequence, a series of short quick scenes is presented as if they were, flashbacks: the character in a family dinner showing him in an uncomfortable position with his family; the character inside his room smashing the air; the character in a basketball game scoring a point and being laughed at by his colleagues. At this moment, some of the characters are presented with blind eyes representing the indifference towards him, instead of defending him from the attacks.

The narrative is back to the persecution and many acts of violence against him are shown. The characters that are inflicting pain in him are shown with open eyes while the others have blind eyes. The exhibition of the videoclip is done through many scenes that emphasized the violence up to the moment of the main character crucifying. The director becomes polemic in this scene when the colleagues shoot the crucified character with firearms. Hearing the school bell ringing, everybody goes back to school leaving him 
alone. The resolution is completed when the music stops and the gaze of the character to the camera in contre-plongèe catches him saying "merci" in French.
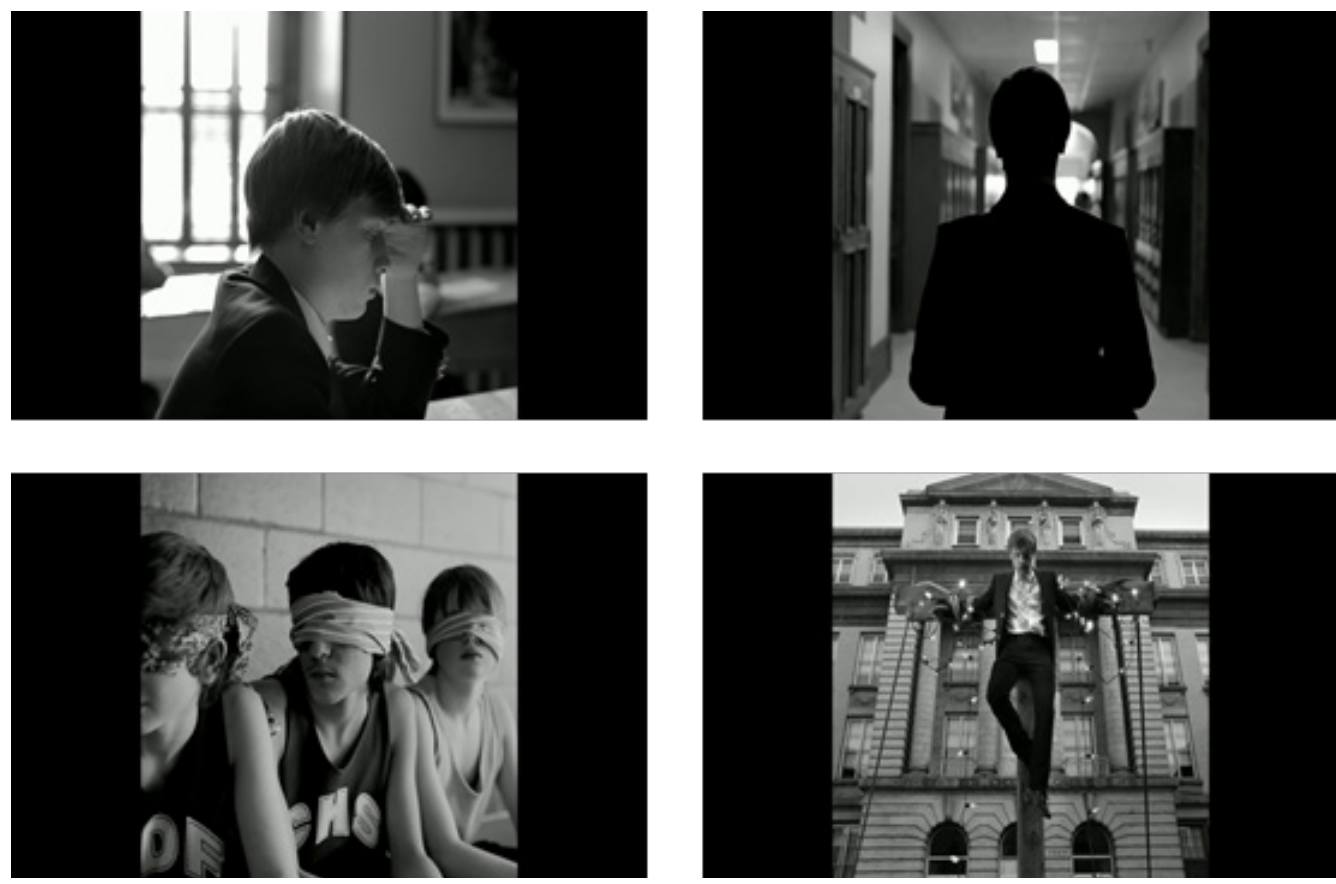

Figure 2: Videoclip frames, music College Boy, Indochine, directed by Xavier Dolan, 2013 Source: https://www.youtube.com/watch?v=Rp5U5mdARgY

College Boy is a narrative-based videoclip. The fact of not showing the band participation does not signalize another time or narrative space. All the scenes are connected to a specific situation and the filmic structure is composed of a linear strategy inserted with short flashbacks. This situation starts in the beginning of the scenes in the classrooms up to the moment of the coffee break and the return inside the classroom. Through this temporal and special development we are exposed to the violence and the thematic debates that are made visible by these narrative strategies

It is possible to verify that in the two clips directed by Xavier Dolan there is a link that exposes the style of narrative representation that is well constructed. The expansion of the narrative is done through quick arrangements, but solid ones since they deconstruct specific categories of the videoclip language. We believe that the habit of telling stories is not lost in contemporary media scenarios considering that it is evident the expansion of narratives in videoclips.

\section{Conclusion}

In this study, we demonstrated how, in the realm of convergent media, the format of the materials produced suffers an adaptation, moulding contents according to the new formulations. We have concentrated our focus on aspects of narrativity in our digital world, focusing in the videoclip language, departing from a path that has been gaining strength due to its articulation with contemporary processes of image and sound. 
Digital storytelling is viewed as a principle for the understanding of narrative insertion in varied contemporary audio-visual formats. We have shown that in the analysed videoclips the sequenciality is mixed with the presence of characters and actions, visualized in fragmented space and time, altered to create dynamic formats. It is relevant to note that in the online YouTube platform, for instance, there is a significant tendency for videoclips that are based on the development of narrative structures similar to the classic profile of the cinematographic narrative, according to the logic order and clarity of principles that define the structure of a story.

Once the characterization of videoclip language was the intense experimental and deconstructive narrative, but nowadays the tendency is to amplify the possibilities. The development of strategies is not limited to the exact time and rhythm of the songs anymore. So we designated as "expanded narratives" the evident narrative amplification that is a consequence of new mediated transpositions.

Finally, we can acknowledge that the perception of digital technology applications may result in global and effective actions. These results are not only limited to mere experimental situations but have given rise to clear tendencies and visible progress: users now are in control of the media, the old "cinematographic" materials gave place to fresh digital content, information is now available online instead of offline, and activities tend to be interactive sessions shared by communities. More important than anything, however, is that users have changed and are now consumers of multimedia materials, eager for updated information and tireless communicators in permanent mobility.

In a future scenario, we can visualize a new profile of media users, not tied up to old and grand formats, but contemplating small and mobile screens. We believe that there will always be a place to tell stories. Even if this digital amplification seems to oppose the idea, storytelling will certainly be present in human interactions.

Translated by Denize Araújo and José Bidarra

\section{BibLIOGRAPHIC REFERENCES}

Alexander, B. (2011). The new digital storytelling: creating narratives with new medias. Santa Barbara: Praeger.

Barboza, E. M. R. (2015). Narrativas digitais: um estudo sobre os videoclipes interativos da banda Arcade Fire. Comunicação e Sociedade, 27, 369-385. doi: 10.17231/comsoc.27(2015).2107

Bellour, R. (1997). Entre-imagens: foto, cinema e vídeo. Campinas: Papirus.

Block, B. (2010). A narrativa visual: criando a estrutura visual para o cinema, TV e mídias digitais. São Paulo: Elsevier.

Bordwell, D. (2005). O cinema clássico hollywoodiano: normas e princípios narrativas. In F. P. Ramos (Ed.), Teoria Contemporânea do Cinema: documentário e narratividade ficcional (pp. 278-279). São Paulo: SENAC. 
Brandão, D. (2010). Cultura participativa. Resenha crítica sobre a obra Convergence Culture - Where Old and New Media Collide; de Henry Jenkins. Comunicação e Sociedade, 18, 245-256. Retrieved from http:// revistacomsoc.pt/index.php/comsoc/article/view/1004/969

Burgess, J. \& Green, J. (2009). YouTube e a revolução digital: como o maior fenômeno da cultura participativa transformou a mídia e a sociedade. São Paulo: Aleph.

Gaudreault, A. \& Jost, F. (2009). A narrativa cinematográfica. Brasilia: Editora Universidade de Brasilia.

Jenkins, H. (2014). Cultura da conexão. São Paulo: Aleph.

Jenkins, H. (2008). Cultura da convergência. São Paulo: Aleph.

Oliva, R. (2015). Por uma estética da hiperestilização: Interconexões de poéticas audiovisuais. Tese de Doutoramento, Universidade Tuiuti do Paraná, Paraná, Brasil.

Oliva, R. (2017). Interconexões de poéticas audiovisuais. Curitiba: Appris.

Rodrigues, P. \& Bidarra, J. (2016). Transmedia storytelling as an educational strategy: a prototype for learning English as a second language. International Journal of Creative Interfaces and Computer Graphics (IJCICG) [Special Issue on the ARTECH 2015 International Conference], 7(2), 55-66.

Rombes, N. (2009). Cinema in the Digital Age. London: Wallflower.

Sousa, M. N. e; Zagalo, N. \& Martins, M . (2012). "Eu Também Posso Propagar Histórias". A Adaptação e as Narrativas Transmediáticas na Era da Participação. Comunicação e Sociedade, 22, 167-183. doi: 10.17231/ comsoc.22(2012).1280

Vernallis, C. (2004). Experiencing music video: aesthetics and cultural context. New York: Columbia University Press.

Vernallis, C. (2013). Unruly media: YouTube, music video and the new digital cinema. New York: Oxford University Press.

Ursyn, A. (2014). Visual and verbal storytelling. In A. Ursyn (Eds.), Computational Solutions for Knowledge, Art, and Entertainment: Information Exchange Beyond Text (pp. 429-455). Hershey PA, USA: IGI Global. doi: 10.4018/978-1-4666-4627-8.cho22

Wolske, J. (2014). Interactive torytelling and experiental learning: the prospect of "vertical narrativity". In F. M. M. Neto (Eds.), Technology Platform Innovations and Forthcoming Trends in Ubiquitous Learning (pp. 194214). Hershey PA, USA: IGI Global. doi: 10.4018/978-1-4666-4542-4.cho11

\section{BiographicAl Notes}

Rodrigo Oliva has a PhD in Communication and Languages, Postgraduate Program in Communication and Languages, from the Universidade Tuiuti of Paraná (2016). He holds a Master in Communication: Media and Culture from the University of Marília (2005). He is a specialist in Praxis and Photographic Speech by the State University of Londrina (2001). Graduated in Social Communication with qualification in Cinema by the Armando Alvares Penteado Foundation (2000). He also teaches the course Social Communication - Advertising and Propaganda of the University of Paraná. He has teaching experience in courses in the Communications curriculum: history, media aesthetics, 
marketing, cinema, television, video and in practice and textual readings.

E-mail: prof.rodrigo.oliva@gmail.com

Universidade Paranaense, Praça Mascarenhas de Moraes, s/n, 87502-080 Umuarama, Brazil

José Bidarra received his PhD in Educational Communications at Universidade Aberta (the Portuguese Open University), where he is currently Professor in the Department of Science and Technology. He is head of the Informatics, Physics and Technology Section (SIFT). He was co-author of the virtual pedagogical model used by Universidade Aberta. His current research interests focus mainly on the application of multimedia and digital media in distance education, including ebooks, games and simulations. Most of the research is conducted at Universidade Aberta and at CIAC (Centre for the Arts and Communication Research, University of Algarve).

E-mail: jose.bidarra@uab.pt

Department of Sciences and Technology, Universidade Aberta,Rua da Escola Politécnica, 141, 1269-001 Lisbon, Portugal

Denize Araujo holds a Post-Doctorate in Cinema by the Universidade do Algarve, Portugal, a PhD in Comparative Literature, Cinema and Arts by the University of California, Riverside, USA and a Master of Arts in Cinema and Arts by the Arizona State University, USA. She is the Coordinator of the Post-Graduate Course in Cinema, a Post Doctorate Supervisor, and a Professor of the Master and Doctorate in Communication and Languages of the Universidade Tuiuti do Paraná. She is a Member of the International Council, of the Publishing Committee and of the Scholarly Review Committee of IAMCR and a Vice-Head of itsVisual Culture WG. She is Curator of the FICBIC - Film Festival of the International Art Biennial of Curitiba. Her research themes are in the areas of Art and Communication.

E-mail: denizearaujo@hotmail.com

Universidade Tuiuti do Paraná - Rua Sydnei Antonio Rangel Santos, 238 - Santo Inacio, Curitiba - PR, 82010-330, Brazil

* Submitted: 19-08-2017

* Accepted: 03-11-2017 